\title{
VIGIAR E SORRIR: arte, vigilância e redistribuições do olhar
}

\author{
Icaro Ferraz Vidal Junior ${ }^{1}$
}

Resumo: Em Surveiller et sourire: Les artistes visuels et le regard numérique (2015), Sophie Limare apresenta um panorama de projetos artísticos contemporâneos que abordam o tema da vigilância. Através de um percurso ancorado na arte contemporânea, a autora mapeia as principais controvérsias em torno da proliferação de dispositivos de vigilância, sobretudo nos espaços públicos. Esta resenha retoma os principais movimentos argumentativos do texto, aprofundando as tensões que o elevado grau de institucionalização de alguns projetos artísticos analisados instaura na definição das fronteiras entre "arte" e "artivismo".

Palavras-chave: Arte contemporânea, vigilância, artivismo.

Abstract: In Surveiller et sourire: Les artistes visuels et le regard numérique (2015), Sophie Limare presents a panorama of artistic projects that approach the subject of surveillance. Through a path anchored in Contemporary Art, the author maps the main controversies around the proliferation of surveillance devices, especially in public space. This review presents the main argumentative movements of the book, deepening the tensions that a high level of institutionalization of some of the analyzed artistic projects brings to the definition of the borders between "art" and "artvism".

Keywords: Contemporary art, surveillance, artvism.

O título do livro de Sophie Limare, Surveiller et sourire ${ }^{2}$ (2015), resume um deslocamento histórico importante entre o contexto descrito por Michel Foucault em seu clássico Surveiller et punir ${ }^{3}$ (2014) e o tempo presente. Embora faça alusão ao investimento de alguns artistas no caráter lúdico da videovigilância, a articulação entre a vigilância e o sorriso parece corroborar a hipótese deleuziana de que já não estamos operando no interior da lógica disciplinar, mas de uma outra, a do controle, na qual precisaríamos começar a suspeitar das "alegrias do marketing" (DELEUZE, 1990). Já não seria a prisão, mas talvez os reality shows, que estariam a orientar a diagramação dos olhares e a distribuição dos papéis de sujeitos e objetos do olhar. Não há nada de propriamente novo nesta nossa leitura de Limare, entretanto, o paradigma emergente, conciliador - como bem formulou Jonathan Crary (1992) - da vigilância e do espetáculo, parece demandar toda uma problematização do estatuto da arte que, não poucas vezes, comparece no pensamento crítico sobre as tecnologias de comunicação como uma redenção possível.

${ }^{1}$ Doutorando no Programa "Erasmus Mundus Joint Doctorate: Cultural Studies in Literary Interzones", nas Università degli studi di Bergamo e Université de Perpignan Via Domitia. E-mail: vidal.icaro@gmail.com.

${ }^{2}$ Vigiar e Sorrir (nossa tradução).

${ }^{3}$ Vigiar e Punir (trad. Raquel Ramalhete). 
A pesquisadora estrutura seu livro em três partes: (In)visibilidades digitais, (Des)continuidades visuais e Controles (re)creativos. Na primeira, sua ênfase recai sobre um conjunto de proposições artísticas e artivistas que exploram a "dialética da (in)visibilidade", através da qual reivindicam uma distribuição simétrica do olhar, monopolizado pelos sistemas de vigilância. Em um segundo movimento, analisa projetos que abordam a vigilância de um ponto de vista estético, o dispositivo funcionando aqui como uma mídia e, neste caso, a (des)continuidade do olhar digital emerge como interesse partilhado pelos projetos em questão. O terceiro conjunto é composto por proposições artísticas que optam por uma perspectiva lúdica em relação aos dispositivos de vigilância, esquivando-se do caráter punitivo e culpabilizador que lhes seria inerente e apostando no jogo. O título do livro e a maior extensão desta terceira parte em relação às outras duas testemunham a aposta da autora neste terceiro aspecto como o eixo mais potente do livro. Quanto a este terceiro grupo de artistas, a autora escreve:

\begin{abstract}
A abordagem deles marca uma nova apropriação do olhar digital da videovigilância. Nosso assujeitamento a uma sociedade de controle tendo se tornado inelutável, suas obras (re)creativas pós-foucaultianas parecem inserir de forma salutar um pouco de 'je(u)' [a autora brinca com as palavras 'eu', em francês 'je', e 'jogo', em francês 'jeu', através da criação de je(u)] na malha reticular do olhar digital, iniciando a emancipação de um indivíduo hipermoderno (in)submisso às tiranias da visibilidade (LIMARE, 2015, p. 17, nossa tradução).
\end{abstract}

Cada capítulo oferece uma descrição de certos aspectos da vigilância contemporânea que serve em seguida à análise dos projetos artísticos. Em (In)visibilidades digitais a questão do espaço aparece como elemento central, a partir da transformação de um regime onde operava a distinção entre "aqui" e "lá" em uma nova assimetria, entre o "(não) ver" e o "(não) ser visto". Esta assimetria é atacada sobretudo politicamente na medida em que cria uma hierarquia definida sem qualquer apelo aos fundamentos da democracia e da república. Projetos como Control the Controllers, de Fra.Biancoshock ou Mabuse Paris Visit Tour, de Renaud Auguste-Dormeuil enfatizam e questionam esta hierarquia. Fra.Biancoshock instala diante das câmeras de vigilância um cartaz semelhante àquele ao qual somos expostos ao fazermos um exame de vista, questionando a suposta acuidade do vigilante. Já o projeto de Auguste-Dormeuil parodia o turismo de massa parisiense, oferecendo aos participantes um tour em um minibus por quatro bairros da cidade. O turismo paranoico proposto pelo artista 
revela aos turistas a localização de mais de 60 câmeras de vigilância, dentre elas a célebre câmera de vigilância do Hotel Ritz, que filmou a última aparição de Lady Diana antes do acidente de carro que lhe tirou a vida. O que está em jogo nestes projetos (e nos demais analisados pela autora neste capítulo) é a transição da lógica do panopticon para uma nova lógica que Jean-Gabriel Ganascia (2009) chama de catopticon e que está vinculada à crescente pulverização do olhar vigilante.

Se as indagações acerca do espaço e das hierarquias que ele abriga estruturam a primeira parte do livro, é o tempo que vem desempenhar este papel no segundo gesto argumentativo da autora. (Des)continuidades visuais tem início com uma retomada da distinção grega entre duas temporalidades que ganham forma nas figuras de Chronos e Kairós para então diagnosticar o desejo contemporâneo de tudo ver e saber ${ }^{4}$. Tal desejo encontrará eco nos desenvolvimentos das tecnologias ópticas e no crescente potencial de armazenamento de dados dos dispositivos de vigilância. Diferentemente da espacialização levada à cabo pela perspectiva renascentista que, a um só tempo inscrevia o sujeito em um ponto de vista privilegiado e estático, a vigilância contemporânea articula um olhar onisciente, onipresente e, neste sentido, potencialmente diacrônico. O controverso projeto de Jamie Wagg a partir das imagens do caso James Bulger é um excelente exemplo da emergência de um novo regime de temporalidade no interior dos circuitos de videovigilância. Em 1993, James Bulger, então com dois anos, foi sequestrado em um centro comercial próximo à Liverpool antes de ser torturado e espancado até a morte por duas crianças de dez e onze anos de idade, tendo sido em seguida abandonado pelas crianças em uma via férrea onde foi, por fim, seccionado por um trem. Wagg imprime em grande formato dois frames extraídos dos registros das câmeras de vigilância: no primeiro, vemos a barragem de terra onde Bulger foi assassinado e no segundo vemos o corredor do supermercado onde o menino foi sequestrado. Nas suas impressões destes frames o artista apaga as indicações de data, hora e lugar, apresentando tais imagens destacadas de seu contexto. Embora muito criticado pela imprensa, pela família da criança e pela opinião pública, as mesmas imagens utilizadas por Wagg já haviam sido amplamente difundidas após o assassinato e legitimaram as demandas por mais vigilância por parte da sociedade civil. O que parece interessar ao argumento de Limare neste projeto é o fato de que o artista joga com o intervalo entre uma certa doçura da imagem capturada (duas crianças de 
costas para a câmera caminhando de mãos dadas com uma criança menor) e a imprevisibilidade de um devir que não se dá a ver na imagem.

O noema da imagem de videovigilância não parece portanto mais afiliado ao passado, mas antes a um futuro anterior, ou seja a um 'isso-terá-sido' que persegue todo desvio potencial e permite visualizar em loop um evento real, fustigando na passagem a irreversibilidade da flecha de Chronos". (LIMARE, 2015, p. 77, nossa tradução).

A terceira parte de Surveiller et sourire, Controles (re)creativos analisa um conjunto de projetos artísticos a partir da ideia de jogo, revisando a distância que tendemos a instaurar entre os universos lúdico e disciplinar. Um dos projetos é o do coletivo Cam Over, que foi levado à cabo com a implementação de um ostensivo aparato de videovigilância na estação de trem de Bonn, na Alemanha, após uma tentativa fracassada de atentado. O coletivo lançou um jogo de realidade virtual no qual propunham aos participantes que estes destruíssem as câmeras e publicassem um vídeo da ação na internet. A autora toma uma posição crítica diante de tal projeto, apostando na potência de iniciativas que em vez de destruírem as máquinas, sejam capazes de reprogramá-las, disputar suas regras, despertando, através do riso, a consciência do que se passa nessas caixas pretas. Este é o caso, por exemplo, de um outro projeto de Renaud Auguste-Dormeuil, Visite guidée à thème: sécurité et patrimoine, que também consiste em uma visita guiada. Desta vez, no entanto, convidado pelo Centre de Création Contemporaine de Tours e posteriormente pelo Palais de Tokyo, Auguste-Dormeuil realiza a visita em espaços expositivos, desvelando o sistema securitário e os constrangimentos impostos pelas seguradoras aos projetos expográficos que, em geral, acreditamos depender exclusivamente de escolhas curatoriais. O espaço do museu, extremamente vigiado, é também o palco de Night Watch, de Francis Alÿs que, em colaboração com a National Gallery de Londres, soltou uma raposa no espaço do museu durante uma noite e registrou este percurso através de vinte câmeras de vigilância do museu. O trabalho é exibido em uma espécie de painel de controle que conta com vinte telas. A reconstituição imaginária do espaço do museu pelo espectador, através das entradas e saídas da raposa de cada imagem dá-se como num jogo de esconde-esconde.

O livro de Sophie Limare em nenhum momento pretende-se exaustivo ou totalizante, mas apresenta uma riqueza analítica e um volume de exemplos que oferecem ao leitor um 
generoso panorama da incorporação política, estética e lúdica, pela arte, dos dispositivos de videovigilância. Pesquisadora no campo da teoria da arte contemporânea, a autora produz um texto cujo interesse excede o campo disciplinar no qual está inserido, e apresenta questões caras não somente aos estudos em tecnologias, políticas e estéticas da comunicação, mas à sociedade civil de um modo mais abrangente. $\mathrm{O}$ fato de não aprofundar conceitualmente a distinção que existiria entre arte e artivismo e de não descrever a inserção institucional de cada projeto analisado - cuja heterogeneidade vai do coletivo underground Cam Over a Ai Weiwei - não tornam o trabalho de Limare menos interessante. Mas fica para o leitor e para próximos estudos a tarefa de mensurar a eficácia crítica de tais projetos. Para isso, será inevitável contextualizar a circulação destes projetos. Se é verdade que o violento jogo proposto por Cam Over pode ser visto como ingênuo, é verdade também que sua inserção na internet e seu apelo junto a um público adolescente, frequentemente alvo dos circuitos de vigilância, repercute no mundo social de uma maneira distinta daquela que os belos trabalhos de Francis Alÿs ou de Ai Weiwei repercutirá.

\section{Referências}

CRARY, Jonathan. Techniques of the Observer: On Vision and Modernity in the Nineteenth Century. Cambridge, MA: MIT press, 1992.

GANASCIA, Jean-Gabriel. Voir et pouvoir: qui nous surveille?. Paris: Éditions Le Pommier, 2009.

GILLES, Deleuze. "Post Scriptum sur les sociétés de contrôle" In: POURPARLERS (19721990). Paris: Éditions de Minuit, 1990.

FOUCAULT, Michel. Surveiller et punir. Naissance de la prison. Paris: Editions Gallimard, 2014.

LIMARE, Sophie. Surveiller et sourire: Les artistes et le regard numérique. Montréal: Les Presses de l'Université de Montréal, 2015. 